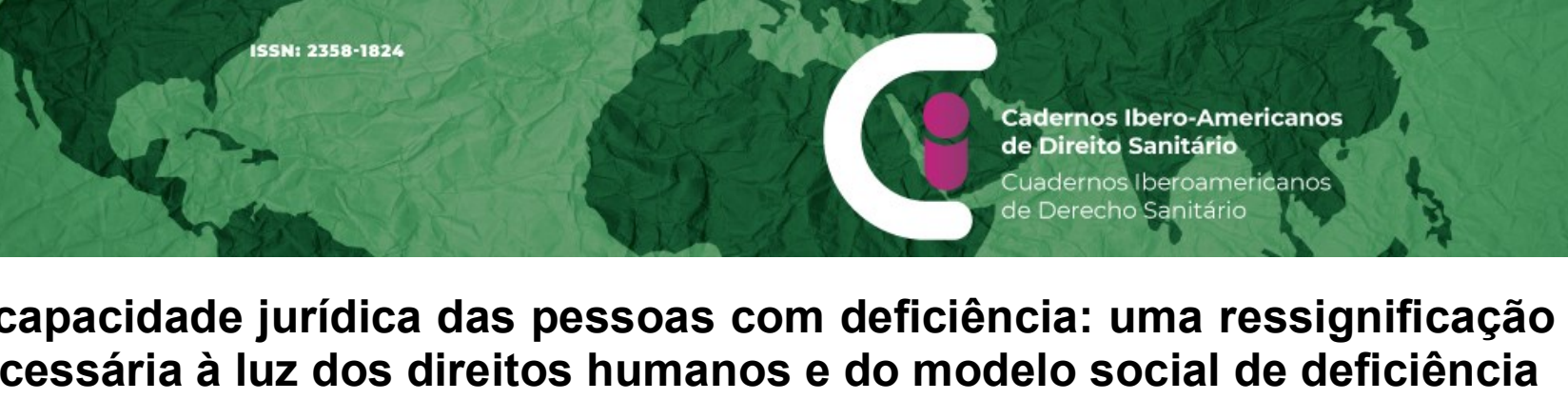

\title{
A capacidade jurídica das pessoas com deficiência: uma ressignificação necessária à luz dos direitos humanos e do modelo social de deficiência
}

The legal capacity of persons with disabilities: a necessary reframing in the light of human rights and the social model of disability

La capacidad jurídica de las personas con discapacidad: resignificación necesaria a la luz de los derechos humanos y del modelo social de discapacidad

Ana Cláudia Mendes de Figueiredo ${ }^{1}$

\begin{abstract}
Resumo
Objetivos: analisar o novo paradigma da capacidade jurídica das pessoas com deficiência, instaurado pelo artigo 12 da Convenção Internacional sobre os Direitos das Pessoas com Deficiência e reiterado pela Lei Brasileira de Inclusão da Pessoa com Deficiência - Lei $n^{\circ}$ 13.146/2015 -, bem como identificar possíveis obstáculos ao reconhecimento da capacidade, em igualdade de condições com as demais pessoas. Metodologia: a pesquisa é qualitativa, documental e bibliográfica, tendo sido baseada em normas constitucionais e legais, em documentos oficiais da Organização das Nações Unidas e em livros e artigos científicos sobre o tema. Resultados: o mapeamento dos óbices que têm desencadeado oposição em relação ao tema permitiu a definição de estratégias para seu enfrentamento, que somente se afigurarão viáveis por meio do empreendimento de esforços amplos para a materialização do direito das pessoas com deficiência ao exercício da sua capacidade, sem discriminação. Conclusão: a superação da resistência às inovações trazidas pela Convenção Internacional sobre os Direitos das Pessoas com Deficiência e repetidas na Lei $n^{\circ} 13.146 / 2015$ pressupõe uma ressignificação do direito à capacidade, à luz dos direitos humanos e do modelo social de deficiência. Pressupõe, ainda, o engajamento de toda a sociedade em um processo crítico, combativo e emancipador, destinado ao rompimento das amarras desencadeadas pelas opressões e usurpações que sempre aprisionaram e alienaram - da sociedade e da História - essas pessoas.
\end{abstract}

\section{Palavras-chave}

Capacidade jurídica. Pessoas com deficiência. Direitos Humanos. Dignidade humana.

\begin{abstract}
Objectives: to analyze the new paradigm of the legal capacity, established by the article 12 of the Convention on the Rights of Persons with Disabilities and reaffirmed by the Brazilian Law of Inclusion of Persons with Disabilities - Law $n^{\circ} 13.146 / 2015$-, as well as to identify possible obstacles of recognizing the capacity on equal terms with others. Methods: this study is qualitative, documental and bibliographic and is based on constitutional and legal norms, official documentation of the United Nations and books and articles on the subject. Results: the mapping of the obstacles that have triggered opposition in relation to the theme allowed the definition of strategies for their confrontation, which will only appear viable through the undertaking of ample efforts for the materialization of the right of persons with disabilities to exercise their capacity with no discrimination. Conclusion: the overcoming of
\end{abstract}

\footnotetext{
1 Advogada; coordenadora do Comitê Jurídico da Federação Brasileira das Associações de Síndrome de Down (FBASD); conselheira no Conselho Nacional dos Direitos das Pessoas com Deficiência (Conade); idealizadora da Rede Brasileira de Inclusão da Pessoa com Deficiência (Rede-In) Brasília, Distrito Federal, Brasil. https://orcid.org/0000-0002-9522-0967. Email: ana.f0703@gmail.com
} 


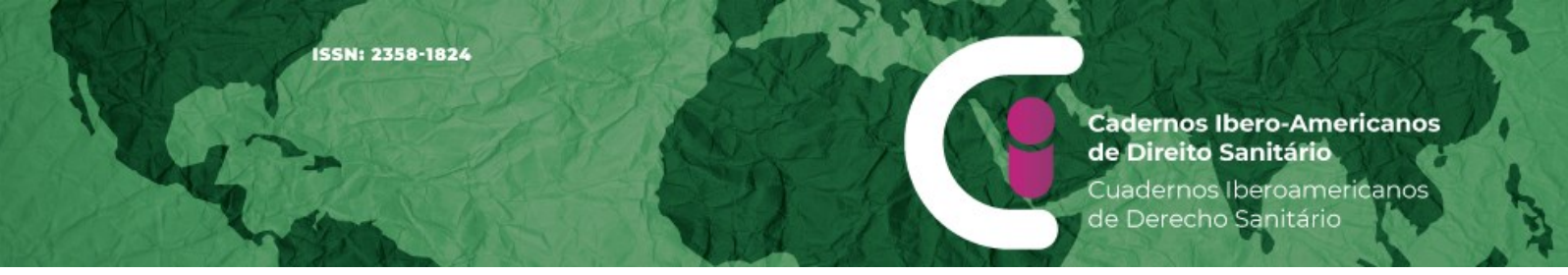

the resistance to the innovations brought by the Convention on the Rights of Persons with Disabilities and repeated on the Law $n^{\circ} 13.146 / 2015$ presupposes reframing of the right considering human rights and the social model of disability. It also presupposes the engagement of the whole society in a critical process, combative and emancipatory, destined to breaking the chains brought about by oppression and usurpation that have always imprisoned and alienated - of society and of history - these persons.

\section{Keywords}

Legal capacity. Disabled persons. Human Rights. Human dignity.

\section{Resumen}

Objetivos: análisis del nuevo paradigma de la capacidad jurídica, establecido por el artículo 12 de la Convención Internacional sobre los Derechos de las Personas con Discapacidad y reiterado por la Ley Brasileña de Inclusión de la Persona con Discapacidad - Ley $\mathrm{n}^{\circ}$ 13.146/2015 -, bien como identificar posibles obstáculos al reconocimiento de la capacidad, en igualdad de condiciones con las demás personas. Metodología: la investigación es cualitativa, documental y bibliográfica, habiendo sido basada en normas constitucionales y legales, en documentos oficiales de la Organización de las Naciones Unidas y en libros y artículos científicos acerca del tema. Resultados: el mapeo de los obstáculos que vienen desencadenando oposición en relación al tema permitió que se definieran estrategias para su enfrentamiento, que solo resultarán viables por medio de la realización de esfuerzos amplios para la materialización del derecho de las personas con discapacidad al ejercicio de su capacidad, sin discriminación. Conclusión: la superación de la resistencia a las innovaciones que trajo la Convención Internacional sobre los Derechos de las Personas con Discapacidad y que se repiten en la Ley $n^{013.146 / 2015}$ presupone una resignificación del derecho a la luz de los derechos humanos y del modelo social de deficiencia. También presupone el envolvimiento de toda la sociedad en un proceso crítico, combativo y emancipador, destinado a romper las cadenas de las opresiones y usurpaciones que siempre encarcelaron y promovieron enajenación de esas personas, tanto de la sociedad cuanto de la Historia.

\section{Palabras clave}

Capacidad jurídica. Personas con discapacidad. Derechos Humanos. Dignidad humana.

\section{Introdução}

Até bem pouco tempo ser pessoa com deficiência ${ }^{2}$, em muitos casos, significava automaticamente não ter capacidade jurídica para praticar atos passíveis de serem praticados pela maioria da população (1), como casar, testemunhar em juízo ou assinar a quitação das verbas rescisórias do seu contrato de trabalho.

Após a Convenção Internacional sobre os Direitos das Pessoas com Deficiência (CDPD) (2), os Estados Partes se viram obrigados, ante o disposto no artigo 12 desse documento, a rever a compreensão arraigada em seus ordenamentos jurídicos, de incapacidade civil das pessoas com deficiência, e a reconhecer que essas pessoas gozam

\footnotetext{
2 Consoante o artigo 1 da Convenção Internacional sobre os Direitos das Pessoas com Deficiência, "Pessoas com deficiência são aquelas que têm impedimentos de longo prazo de natureza física, mental, intelectual ou sensorial, os quais, em interação com diversas barreiras, podem obstruir sua participação plena e efetiva na sociedade em igualdades de condições com as demais pessoas" (2).
} 
de capacidade legal em igualdade de condições com os demais indivíduos, em todos os aspectos da vida.

A CDPD, que teve como fonte de inspiração o direito internacional dos direitos humanos e o modelo social de deficiência (3), foi aprovada em 2008, pelo Congresso Nacional brasileiro, com valor de emenda constitucional, e promulgada mediante o Decreto $n^{\circ} 6.949$, de 25 de agosto de 2009 (2).

Na esteira do disposto no artigo 12 da CDPD, a Lei $n^{\circ} 13.146 / 2015$, Lei Brasileira de Inclusão da Pessoa com Deficiência (LBI), também denominada de Estatuto da Pessoa com Deficiência (4), promoveu alterações na legislação que disciplina a capacidade das pessoas, com vistas ao rompimento da identificação entre deficiência e incapacidade civil, o que desencadeou perplexidade e inconformismo em vários segmentos sociais, como, por exemplo, a comunidade jurídica, conforme se pode verificar em Coelho FU (5); Venosa SS (6); Fiuza C (7); Tomazette M e Araújo RAC (8) e Kümpel VF e Borgarelli BA (9).

A resistência da sociedade em relação ao novel arquétipo da capacidade jurídica também constatada em outros espaços sociais, a partir da militância que se faz em prol da efetivação dos direitos das pessoas com deficiência, e denunciada em artigos e livros jurídicos sobre o tema $(10,11)$ - gerou a necessidade de refletir sobre as aludidas normas. Gerou, também, a necessidade de identificar os fatores que têm desencadeado o mencionado antagonismo e impedido, conforme apontado nas Observações Finais sobre o informe inicial do Brasil (12), do Comitê da Organização das Nações Unidas sobre os Direitos das Pessoas com Deficiência ${ }^{3}$, a concretização do referido arquétipo, que materializa o direito humano ao exercício da capacidade jurídica por parte de todas as pessoas com deficiência. A constatação quanto à citada resistência desencadeou ainda o interesse de buscar estratégias de enfrentamento que possam contribuir para a derrubada das barreiras - especialmente normativas, atitudinais e de acessibilidade -, que seguem inviabilizando a realização do novo paradigma e um pensar dignificante sobre esses novos sujeitos de direitos e obrigações.

$\mathrm{O}$ artigo tem por objetivo analisar o novo paradigma da capacidade jurídica das pessoas com deficiência, instaurado pelo artigo 12 da CDPD e reiterado pela LBI, bem como identificar possíveis obstáculos à concretização do direito ao reconhecimento da capacidade, em igualdade de condições com as demais pessoas.

3 O Comitê realiza, no âmbito da ONU, o monitoramento internacional das obrigações contraídas pelos Estados partes da CDPD. 
Para melhor compreensão, o artigo foi estruturado em cinco seções, além da introdução, metodologia e considerações finais. Inicialmente, discutiu-se sobre os cinco parágrafos do artigo 12 da Convenção e sobre a compreensão do Comitê da Organização das Nações Unidas sobre os Direitos das Pessoas com Deficiência a respeito de alguns aspectos dessa norma. Na sequência, foram feitas breves considerações acerca do modelo social da deficiência e sobre as alterações legislativas promovidas pela LBI, por força da ratificação da CDPD pelo Estado brasileiro. Após, foram referidos alguns desafios à realização do novo paradigma da capacidade jurídica e apontadas algumas transformações e avanços necessários à materialização do artigo 12 da CDPD.

\section{Metodologia}

Trata-se de pesquisa teórica e documental sobre um tema cuja bibliografia ainda não é extensa no Brasil, a saber, as repercussões do artigo 12 da Convenção sobre os Direitos das Pessoas com Deficiência (CDPD) e da Lei Brasileira de Inclusão da Pessoa com Deficiência (LBI) em relação à capacidade jurídica dessa população.

A investigação foi empreendida com o intuito de i) analisar o novo paradigma da capacidade jurídica, de reconhecimento da capacidade jurídica das pessoas com deficiência, em igualdade de condições com as demais pessoas, e ii) identificar alguns dos obstáculos à concretização desse direito humano.

Para o atingimento de tais objetivos, foram adotados procedimentos de cunho documental e bibliográfico. No plano internacional, os documentos analisados foram a Convenção sobre os Direitos das Pessoas com Deficiência (2), especialmente os seus artigos $3^{\circ}$ e 12, o Comentário Geral $n^{\circ} 1$ sobre o artigo 12 (13) e as Observações Finais sobre o informe inicial do Brasil (12). No plano nacional, foram examinados principalmente os reflexos das modificações determinadas pelos artigos $114(4)$ - que alterou os artigos $3^{\circ}$ e $4^{\circ}$ do Código Civil (14) - e 116 da LBI (4), que introduziu o instituto da tomada de decisão apoiada no Código Civil (artigo 1783-A).

A pesquisa contemplou livros e artigos científicos sobre capacidade jurídica, direitos das pessoas com deficiência e direitos humanos, publicados em português, inglês e espanhol. Os artigos científicos, assim como alguns livros, foram obtidos em bancos de dados abertos do governo federal, das Nações Unidas, de universidades, do Comité Español de Representantes de Personas com Discapacidad, da Scielo, entre outros. Foram utilizadas como indexadores as expressões capacidade jurídica, capacidade civil e pessoa com 
deficiência. O recorte temporal deu-se a partir de agosto de 2009 , data em que iniciou a vigência, no Brasil, da Convenção sobre os Direitos das Pessoas com Deficiência (CDPD), em decorrência da sua promulgação pelo Decreto n 6.949, de 25 de agosto de 2009 .

No artigo foram explicitados alguns dos possíveis obstáculos que as pessoas com deficiência têm encontrado para exercer seu direito à capacidade jurídica e enumeradas algumas transformações que precisariam ser promovidas pelos poderes públicos e pela sociedade em geral, para a materialização plena do artigo 12 da CDPD (2).

\section{A Convenção sobre os Direitos das Pessoas com Deficiência (CDPD) e o seu controvertido artigo 12}

A consagração, no texto do artigo 12 da Convenção, do reconhecimento da capacidade jurídica das pessoas com deficiência resultou do debate mais acirrado de todo esse documento, consubstanciando, ao final, a regra mais inovadora e desafiadora da CDPD, especialmente em relação a pessoas com determinados impedimentos, como os de natureza intelectual e, em alguns casos, mental ou psicossocial (3).

No item 1 do artigo 12 da Convenção, os Estados Partes reafirmaram que as pessoas com deficiência "[...] têm o direito de ser reconhecidas em qualquer lugar como pessoas perante a lei [...]", enfatizando, no preâmbulo (2), o que já havia sido previsto em outros documentos internacionais em relação às pessoas em geral. O registro de tal direito, aparentemente óbvio, foi importante porque o reforça, impondo aos signatários da CDPD o deslocamento do alvo precípuo de amparo até então adotado pelos Estados Partes: o patrimônio para o indivíduo (10). Em outras palavras, a proteção legal, antes destinada essencialmente ao resguardo do patrimônio das pessoas com deficiência, passou a ter como alvo primordial sua dignidade, o que permitiu que fosse reconhecido o direito ao exercício da sua capacidade jurídica e assegurada, consequentemente, sua inclusão e participação plena e efetiva na sociedade. As pessoas com deficiência deixaram de ser simples objetos de tutela e destinatárias apenas de políticas assistenciais, de natureza meramente caritativa (1), para serem destinatárias de políticas que promovem sua autonomia e cidadania, em uma perspectiva emancipatória.

O segundo item do artigo 12 determinou o reconhecimento, pelos Estados Partes, de que as pessoas com deficiência "[...] gozam de capacidade legal em igualdade de condições com as demais pessoas em todos os aspectos da vida [...]" (2). Ante o teor dessa norma e do disposto nos artigos 3 e 5 da CDPD, a capacidade dessas pessoas somente poderá ser 
limitada pelas legislações nacionais, com base em critérios impostos genericamente (13). Significa dizer que a capacidade não mais poderá ser restringida em razão de deficiência, mas apenas em face de critérios universais, frente aos quais qualquer pessoa, com ou sem deficiência, poderá ter sua capacidade mitigada.

Ao esclarecer a amplitude dessa norma, o Comitê da Organização das Nações Unidas sobre os Direitos das Pessoas com Deficiência afirmou, no Comentário Geral $n^{\circ} 1$, que os déficits, supostos ou reais, na capacidade mental - entendida como aptidão para tomar decisões - não devem ser invocados como justificação para negar a capacidade jurídica a alguma pessoa (13, p. 4). Assinalou, ainda, que a CDPD deixa claro que também não são razões legítimas para tanto "[...] o 'desequilíbrio mental' e outras denominações discriminatórias [...]" (13, p. 4, tradução livre), sendo imperativo o reconhecimento da "[...] capacidade jurídica universal, em virtude da qual todas as pessoas, independentemente de sua deficiência ou da sua aptidão para tomar decisões, possuem uma capacidade jurídica inerente [...]" (13, p. 7, tradução livre).

O Comitê asseverou, por fim, que o artigo 12 da Convenção afirma que "[...] todas as pessoas com deficiência têm plena capacidade jurídica [...]" (13, p. 2, tradução livre), sendo abrangida por essa tanto a capacidade de ser titular de direitos e obrigações quanto a capacidade de exercer tais direitos e obrigações (13, p. 4). Essa compreensão é corroborada também pelo conteúdo do item 5 desse artigo (2), a seguir comentado, e exteriorizada por Ferraz e Salomão (1).

A fim de garantir que o direito em debate não sofra mitigação em razão da deficiência, a Convenção determinou que os Estados Partes adotem medidas apropriadas para prover o acesso de pessoas com deficiência ao apoio de que necessitem para o exercício da sua capacidade. O apoio, cumpre dizer, constitui o fundamento do novo sistema instaurado pela Convenção, equivalendo a "[...] um termo amplo que engloba arranjos oficiais e extraoficiais de distintos tipos e intensidades [...]" (13, p. 5, tradução livre).

A CDPD também impôs que as medidas relativas ao exercício da capacidade jurídica incluam salvaguardas apropriadas, proporcionais e efetivas para prevenir abusos, garantir o respeito aos direitos, à vontade e às preferências das pessoas com deficiência e assegurar a isenção de conflito de interesses e de influência indevida (2).

Por fim, no item 5 do artigo 12, a Convenção compeliu os Estados Partes a assegurarem às pessoas com deficiência igual direito de possuir ou herdar bens, de controlar as próprias finanças e de ter igual acesso a empréstimos bancários, hipotecas e outras 
formas de crédito financeiro, garantindo que não sejam arbitrariamente destituídas de seus bens (2). Esse item traduz, segundo o Comitê da ONU, o direito ao reconhecimento dessas pessoas como atores jurídicos, o que significa dizer que são autorizadas "[...] a realizar transações e criar, modificar ou encerrar relações jurídicas." (13, p. 3, tradução livre).

Todas essas disposições refletem o intuito dos Estados signatários de avançar, em termos de garantia de direitos, até uma "[...] perspectiva da deficiência baseada nos direitos humanos [...]", pautada pelos valores da dignidade, da liberdade e da igualdade (3).

\section{Modelo social de deficiência}

A consideração da deficiência como uma questão de direitos humanos foi determinante para o acolhimento, pela comunidade internacional, do modelo social, que tem como fundamentos os princípios da vida independente, não discriminação, acessibilidade universal, normalização do ambiente, entre outros, e como objetivos a promoção do respeito pela dignidade humana, a igualdade e a liberdade pessoal, o que propicia inclusão social (3).

Consoante o modelo social de deficiência, que ainda se apresenta "[...] como um reclamo, uma aspiração, um ideal a ser alcançado [...]" (3), a participação social plena e efetiva - em igualdade de condições - das pessoas que têm algum impedimento nas funções ou estruturas do corpo depende do empenho de toda a sociedade para eliminar toda e qualquer barreira que inviabilize o exercício da cidadania e a inclusão social. Essa ideia consolida o caráter relacional da deficiência (1).

Segundo Bampi, Guilhem e Alves, o modelo social é uma corrente teórica e política que se contrapôs ao modelo médico dominante. Com a adoção desse modelo "[...] a deficiência deixa de ser um problema trágico, de ocorrência isolada de alguns indivíduos menos afortunados, para os quais a única resposta social apropriada é o tratamento médico (modelo médico) [...]", passando a ser considerada como "[...] uma situação de discriminação coletiva e de opressão social para a qual a única resposta apropriada é a ação política [...]" (15). Os esforços, nesse modelo, “[...] deveriam concentrar-se em modificar as estruturas que provocavam ou reforçavam a deficiência, ao invés de apenas tentar curar, tratar ou eliminar as lesões ou incapacidades[...]" (15).

No Brasil a transformação das estruturas que geram e reforçam a deficiência ganhou impulso com uma série de alterações legislativas promovidas pela Lei $n^{0} 13.146 / 2015$, as 
quais vêm contribuindo para a adequação gradual do ordenamento jurídico pátrio aos princípios e disposições da Convenção - e ao modelo social de deficiência.

\section{As repercussões da ratificação da Convenção sobre os Direitos das Pessoas com Deficiência (CDPD) na legislação nacional}

Em atenção ao disposto no artigo 12 da Convenção, a Lei Brasileira de Inclusão da Pessoa com Deficiência (LBI) estabeleceu que "[...] a deficiência não afeta a capacidade civil da pessoa [...]" (art. $6^{\circ}$ ) e introduziu, em nosso ordenamento, o instituto da tomada de decisão apoiada (2). A LBI promoveu ainda, paralelamente, várias mudanças no Código Civil brasileiro (14), desconstruindo a tradicional teoria das incapacidades.

De fato, a LBI, na linha da CDPD, reconheceu às pessoas com deficiência o "[...] direito ao exercício da sua capacidade legal [...]", em igualdade de condições com as demais pessoas (4), inclusive em relação a vários direitos nunca garantidos à parte dessa população, como as pessoas com deficiência intelectual e, em alguns casos, mental ou psicossocial. São exemplos desses novos direitos o direito ao casamento e à constituição de união estável, ao exercício de direitos sexuais e reprodutivos e ao exercício do direito à guarda, à tutela, à curatela e à adoção (4).

Além desses direitos, a LBI assegurou outros direitos importantes à concretização da participação plena e efetiva das pessoas com deficiência na sociedade - sempre em igualdade de oportunidades com as demais pessoas -, a exemplo do direito de acesso à justiça; direito à acessibilidade indispensável à vida independente e ao exercício dos direitos de cidadania e de participação social; direito à privacidade; direito à participação na vida pública e ao exercício de direitos políticos; direito de obter a prestação de serviços notariais e de registro sem óbices ou condições diferenciadas e direito a documentos oficiais, independentemente de curatela, entre outros (4).

A garantia do exercício de tais direitos materializa os princípios constitucionais da cidadania, da dignidade da pessoa humana e da isonomia (16) e efetiva o respeito à autonomia individual, inclusive a liberdade de fazer suas próprias escolhas, mesmo que com apoio. O valor da autonomia baseia-se, cumpre lembrar, "[...] no pressuposto de uma capacidade de ação e de comportamento autodirigido", apoiando-se na "[...] imagem implícita de uma pessoa moralmente livre [...]" (3).

Além de estabelecer como regra a capacidade jurídica plena, dissociando a deficiência da incapacidade, a LBI revogou os dispositivos do Código Civil que incluíam entre 
os relativamente incapazes "[...] os que, por deficiência mental, tenham o discernimento reduzido [...]" e "os excepcionais, sem desenvolvimento mental completo[...]" (4). Revogou também dispositivo que considerava como absolutamente incapazes os que, "[...] por enfermidade ou deficiência mental, não tiverem o necessário discernimento[...]" para a prática de atos da vida civil (4). Essas circunstâncias deixaram, assim, de ser causas de incapacidade absoluta ou relativa.

A LBI também deslocou a hipótese de impossibilidade de expressão da vontade, do rol da incapacidade absoluta para o rol da incapacidade relativa (4). Com isso, a única hipótese de incapacidade absoluta que remanesceu no ordenamento jurídico pátrio foi a de pessoa menor de dezesseis anos. Já as hipóteses de incapacidade relativa passaram a abranger - além dos ébrios habituais, viciados em tóxico, pródigos e maiores de dezesseis anos e menores de dezoito - aqueles que, por causa transitória ou permanente, não puderem exprimir sua vontade (4). Essas causas, extensíveis a todas as pessoas - com e sem deficiência -, não mais fazem menção, como dito, a desenvolvimento mental ou discernimento.

Por fim, a LBI incluiu, no Código Civil, o art. 1783-A, que lança os fundamentos da tomada de decisão apoiada, instituto segundo o qual a pessoa com deficiência pode eleger pessoas da sua confiança para apoiá-la no exercício da sua capacidade jurídica, que se mantém inalterada (4).

Como visto, o Brasil já avançou na implementação do artigo 12 da CDPD, mas ainda não o suficiente, segundo o Comitê da ONU (13), a conformar plenamente a legislação pátria com a Convenção. Para tanto, é preciso, entre outros aspectos, ampliar, consistente e urgentemente, a conscientização da sociedade em relação ao direito estabelecido na CDPD, a fim de arrefecer a oposição de vários segmentos da sociedade ao paradigma da capacidade jurídica universal (13), para que seja plenamente realizado. Além do citado esforço, é imperioso discernir algumas das motivações que têm determinado o antagonismo constatado em relação ao tema.

\section{Alguns dos possíveis obstáculos à realização do novo paradigma da capacidade jurídica}

A resistência da sociedade em relação às profundas modificações no que diz respeito à capacidade jurídica das pessoas com deficiência - inauguradas pela Convenção e 
ratificadas, em relativa medida, pela $\mathrm{LBI}$ - tem raízes em motivos variados ${ }^{4}$, alguns dos quais vale menção.

Uma primeira razão tem a ver com o desconhecimento, por parte da sociedade em geral, do modelo social de deficiência (17), que rege toda a Convenção e consubstancia a compreensão de que a deficiência deve ser determinada a partir de uma perspectiva relacional e global, considerando o impacto que os fatores sociais, econômicos, ambientais - e outros - geram nas atividades e na participação social plena e efetiva das pessoas com deficiência.

Um segundo motivo consiste em estar cristalizada, no seio social, a ideia de que pessoas com deficiência, especialmente intelectual e, em alguns casos, psicossocial, são eternas crianças, seres angelicais destituídos de condições para tratarem de questões atinentes à vida adulta e autônoma e, consequentemente, para exercerem sua capacidade jurídica, ainda que com apoio (17). Em face de motivações dessa ordem, a curatela continua sendo requerida pelas famílias - e não raramente decretada pelo Judiciário -, mesmo nos casos em que as pessoas com deficiência conseguem exprimir sua vontade.

Uma terceira causa que tem determinado o rechaço ao novo paradigma, integrante do sistema de decisão apoiada, é o receio, por parte de familiares de pessoas com deficiência, de que a opção por esse sistema "[...] prejudique o direito dos seus filhos/irmãos ao recebimento de benefício previdenciário ou assistencial." (17), acarretando o desamparo desses dependentes. Vale registrar que, embora esse receio só tenha alguma razão de ser a partir da maioridade previdenciária, que ocorre aos vinte e um anos (18 e 19), o temor das famílias, de desproteção dos seus dependentes, surge muito frequentemente antes da maioridade civil, que se dá aos dezoito anos. A preocupação mais comum entre os familiares ocorre em relação à pensão por morte, garantida aos dependentes com "[...] deficiência intelectual ou mental ou deficiência grave [...]"5 nas Leis $n^{\circ}$ s 8.112/90 (18) e 8.213/91 (19), entre outros diplomas.

Uma quarta motivação, não menos importante, consiste na primazia “[...] da visão centrada na proteção do patrimônio da pessoa com deficiência, própria do Código Civil, em detrimento de uma visão pautada na dignidade da pessoa [...]" (11 e 17). Tal concorre para o entendimento, no mundo jurídico, de que é imprescindível a sujeição das pessoas sem

\footnotetext{
${ }^{4}$ Outros possíveis motivos encontram-se listados no capítulo "A capacidade jurídica das pessoas com deficiência: um novo paradigma construído sob a égide dos direitos humanos" (3).

${ }^{5}$ Expressões adotadas nas Leis n's 8.112/90 (18) e 8.213/1991 (19).
} 
discernimento ou com discernimento reduzido à curatela para sua proteção legal. Essa compreensão encontra-se presente, por exemplo, em Coelho (5), Fiuza (7) e Tomazette e Araújo (8).

É inequivocamente complexo e difícil o enfrentamento das causas determinantes da perpetuação do modelo de substituição na tomada de decisões, mas rigorosamente impositivo para que se consolide no país o novo paradigma da capacidade jurídica e do sistema de apoio na tomada de decisões, pelo qual se assegura à pessoa com deficiência o direito de eleger os rumos da própria vida, ainda que com apoio. Esse intuito deve ser um ideal a ser perseguido por todos os defensores dos direitos humanos dessa população.

\section{As transformações e avanços necessários à materialização do artigo 12 da CDPD}

A concretização da capacidade jurídica universal (13) exige transformações significativas e avanços corajosos por parte do Estado, das famílias, dos operadores do Direito, das próprias pessoas com deficiência, das suas organizações representativas e da sociedade em geral (17).

Ao Poder Legislativo cabe seguir promovendo as alterações legislativas imprescindíveis à adequação do ordenamento jurídico ao conteúdo da Convenção, sem retrocessos, a fim de evitar negativas de direitos e insegurança jurídica. Consoante afirmado por Quinn, “[...] um novo contrato social com consequentes mudanças legais é necessário para criar espaço para implementação do novo paradigma [...]” (20).

É oportuno registrar que não é razoável que a garantia de reconhecimento de igual capacidade em relação a pessoas com deficiência que antes contavam com proteções legais - asseguradas quando elas eram consideradas como absoluta ou relativamente incapazes - conduza à perda de tais proteções. Um exemplo de amparo desse gênero é o parágrafo único do artigo 928 do Código Civil segundo a qual a indenização nele prevista não será cabível "[...] se privar do necessário o incapaz ou as pessoas que dele dependem." (14). O referido desamparo ocorreria, por exemplo, com uma pessoa com deficiência intelectual que, estando sujeita à curatela, optasse pela tomada de decisão apoiada.

É imprescindível que o Legislativo encontre soluções legais para assegurar que essas pessoas possam exercer o novo direito sem perder outros que já lhes tinham sido garantidos. A ausência de tais soluções implicará afronta ao item 4 do artigo 4 da CDPD, ao princípio do não retrocesso e aos princípios e propósito desse documento internacional (2), bem como esvaziará o instituto da tomada de decisão apoiada (21). Como bem lembrado por Meneses, 
"[m]igramos de um modelo protetivo de substituição de vontade para um modelo pautado no apoio que busca favorecer a emancipação do sujeito sem lhe negar a proteção de que necessitar [...]" (10). Albuquerque, na mesma linha, assinala que, "[...] se o ponto central é a proteção da pessoa tida como 'incapaz', o que se deve priorizar são as formas de protegêla, comprovadamente eficazes [....]" (11), entre as quais se enquadram, as concretizadas pela lei, especialmente a Lei $n^{\circ} 10.406 / 2002$.

Ao Poder Executivo incumbe adotar todas as medidas necessárias à concretização do direito ao reconhecimento da capacidade jurídica das pessoas com deficiência. Nessa perspectiva, deveria, por exemplo, revogar todos os dispositivos da Instrução Normativa $n^{\circ}$ 77 , de 21 de janeiro de 2015, que ainda condicionam o reconhecimento do filho ou irmão maior de 21 anos como dependente do segurado do RGPS à comprovação judicial de incapacidade absoluta ou relativa "[...] por meio de termo de curatela ou cópia da sentença de interdição[...]" (22), o que é incompatível não apenas com a Convenção (2), mas também com os artigos $6^{\circ}$ e 84 da LBI (4), 110-A da Lei 8.213/1991 (19) e 222, § 8º da Lei 8.112/906 (18), bem como com o artigo $7^{\circ}, \S 2^{\circ}$, II, da Portaria Conjunta $n^{\circ} 3$, de 21 de setembro de $2018(23)$.

Outra iniciativa relevantíssima do Estado seria a promoção de campanhas de conscientização da sociedade sobre o novo paradigma da capacidade jurídica e os demais direitos desse decorrentes, em formatos acessíveis, inclusive linguagem simples, com vistas i) à reformulação da sua percepção acerca das pessoas com deficiência, a partir das lentes do modelo social da deficiência, e consequente (re)conhecimento desses novos sujeitos de direitos e dos direitos humanos dessa população; ii) à eliminação de barreiras, principalmente atitudinais e comunicacionais, necessária para viabilizar a participação das pessoas com deficiência nas diversas esferas da vida e iii) à reinvenção dos direitos humanos, apta a desencadear processos de luta pela dignidade humana e por um acesso igualitário e não hierarquizado a priori “[...] aos bens que fazem com que a vida seja 'digna' de ser vivida [...]" (24).

Conforme a International Disability Caucus, organização não governamental que atuou nos trabalhos de elaboração da Convenção, a capacidade jurídica é uma construção social que reflete as eleições das sociedades em determinado momento histórico (3). Sendo assim, incumbe aos poderes públicos tornar esse reflexo o mais consentâneo possível com

${ }^{6} \mathrm{O}$ parágrafo $8^{\circ}$ do artigo 222 da Lei $n^{\circ} 8.112 / 90$ foi incluído pela Lei $n^{\circ} 13.846 / 2019$. 
a hegemonia dos direitos humanos consubstanciada na Convenção. Isso porque o Brasil aprovou esse documento internacional e o ratificou com valor de emenda constitucional, pelo que as escolhas do país a respeito do tema devem coincidir com aquelas gravadas na CDPD.

Aliado ao empenho dos poderes públicos, as famílias, especialmente de pessoas com deficiência intelectual e psicossocial, precisam passar a ver seus familiares como adultos quando maiores de idade, por certo -, sujeitos de direitos e deveres, que têm vontades e preferências que precisam ser respeitadas.

Concretizar o cenário remodelado da capacidade requer ainda o empoderamento (emancipação) das pessoas com deficiência - a ser incentivado por todos aqueles com quem convivem -, o que é importante para a apropriação dos seus direitos e, em última análise, para a realização do ideal de dignidade. O despertamento do poder pessoal existente em cada uma dessas pessoas pode ocorrer i) por meio do conhecimento dos seus deveres e direitos, apto a viabilizar sua participação na sociedade de forma efetiva, plena e em igualdade de condições com as demais pessoas; ii) por meio de vivências emancipatórias e iii) por meio da conscientização sobre seu próprio valor. Com isso, pessoas com algum impedimento passarão a se perceber como cidadãos/cidadãs, que fazem escolhas, decidem, participam da vida em comunidade e transformam o mundo em que vivem (17).

De igual modo, as comunidades precisam reconhecer os direitos das pessoas com deficiência e respeitá-los, bem como acolhê-las, mediante atitudes não infantilizadas e positivas e assistência eventualmente necessária ao exercício de uma vida autônoma, concretizando uma inspiradora rede de apoios (17).

A efetivação do novo paradigma exige por fim empenho por parte dos operadores do Direito, notadamente advogados, defensores públicos e membros do Poder Judiciário e Ministério Público, no sentido de compreender toda a extensão e profundidade do artigo 12 da CDPD. Alcançando essa compreensão, imprimirão, em suas respectivas atuações, interpretações jurídicas harmônicas com os princípios consagrados na Constituição da República e no CDPD, especialmente com os princípios da autonomia, independência, dignidade da pessoa humana e igualdade, o que concorrerá para reformulações importantes no campo da doutrina e da jurisprudência (17).

Cumpre assinalar que o Comitê de monitoramento da Convenção recomendou ao Brasil, nas conclusões do relatório inicial do país, que todas as pessoas com deficiência sob curatela sejam informadas sobre o novo regime instituído de tomada de decisão apoiada e 
que o Estado garanta a elas o exercício do direito a esse novo sistema em qualquer caso $(12)$.

Somente com a atuação convergente do Estado e de toda a sociedade para remover as barreiras impeditivas da participação plena e efetiva das pessoas com deficiência ${ }^{7}$ na vida em comunidade, será possível corrigir as profundas desvantagens sociais vividas por elas. Essa atuação convergente também é fundamental para materializar o propósito da Convenção de promover, proteger e assegurar o exercício ilimitado e equitativo de todos os direitos humanos e liberdades fundamentais das pessoas com deficiência (2), entre os quais o direito ao reconhecimento da plena capacidade jurídica, ainda que seja necessário algum apoio para o seu exercício.

\section{Considerações finais}

A concretização do sistema de apoio inaugurado pela Convenção sobre os Direitos das Pessoas com Deficiência (CDPD) pressupõe o engajamento de toda a sociedade em um processo crítico, combativo e emancipador, destinado ao rompimento das amarras das opressões e usurpações que sempre aprisionaram e alienaram, da sociedade e da História, as pessoas com deficiência. Somente assim será possível torná-las protagonistas das suas trajetórias e capazes de modificar os respectivos destinos e conduzir as próprias vidas.

O empenho de todos em um pensar dignificante em relação a esses sujeitos de direitos propiciará que mais rapidamente seja materializado o direito dessa população ao exercício da sua capacidade jurídica, expressão da sua dignidade.

A implementação do atual paradigma da capacidade jurídica das pessoas com deficiência, especialmente intelectual e psicossocial, é tarefa imprescindível à concretização dos direitos humanos dessas pessoas e à realização, na dimensão vital de cada uma, da sua autonomia - hábil a gerar nelas a percepção de pertencimento ao mundo - e do protagonismo capaz de humanizar a existência e dar sentido à vida.

\section{Referências}

1. Ferraz CV, Salomão GL. A presunção de capacidade civil da pessoa com deficiência na Lei Brasileira de Inclusão. Direito e Desenvolvimento [Internet]. 2016 [citado em 15 dez. 2019];7(13):99-117. Disponível em: https://periodicos.unipe.br/index.php/direitoedesenvolvimento/article/view/303.

\footnotetext{
${ }^{7}$ Albuquerque sustenta que o modelo de apoio para o exercício da capacidade jurídica determinado pela Convenção estende-se a "adultos com vulnerabilidade acrescida" (20), como é o caso, não raramente, de pessoas idosas (11).
} 
2. Brasil. Decreto $n^{\circ} 6.949$, de 25 de agosto de 2009 [Internet]. Promulga a Convenção Internacional sobre os Direitos das Pessoas com Deficiência e seu Protocolo Facultativo, assinados em Nova York, em 30 de março de 2007. Brasília; 26 ago 2009 [citado em 7 dez. 2019]. Disponível em: http://www.planalto.gov.br/ccivil_03/_ato20072010/2009/decreto/d6949.htm

3. Palacios A. El modelo social de discapacidad: Orígenes, caracterización y plasmación en la Convención Internacional sobre los Derechos de las Personas con Discapacidad [internet]. Madrid: Ediciones Cinca; 2008 [citado em 20 nov. 2019]. Disponível em: https://www.cermi.es/sites/default/files/docs/colecciones/EImodelosocialdediscapacidad.pdf

4. Brasil. Lei no 13.146, de 6 de julho de 2015 [Internet]. Institui a Lei Brasileira de Inclusão das Pessoas com Deficiência (Estatuto da Pessoa com Deficiência). Brasília; 7 jul. 2015 [citado em 7 dez. 2019]. Disponível em: http://www.planalto.gov.br/ccivil_03/_ato20152018/2015/lei/l13146.htm

5. Coelho FU. Curso de Direito Civil: Parte Geral. 5a ed. Saraiva: São Paulo; 2012.

6. Venosa SS. Direito Civil: Direito de Família. 16ª ed. São Paulo: Atlas; 2016.

7. Fiuza C. Direito Civil: curso completo. $18^{a}$ ed. São Paulo: Ed. Revista dos Tribunais; 2015.

8. Tomazette $M$, Araújo RAC. Crítica à nova sistemática da incapacidade de fato segundo a Lei 13.146/15: Estatuto da Pessoa com Deficiência. Revista Jus Navigandi [Internet]. 2015 [citado em 27 jan. 2020]:4449: Disponível em: https://jus.com.br/artigos/42271.

9. Kümpel VF, Borgarelli BA. A destruição da teoria das incapacidades e o fim da proteção aos deficientes. Migalhas [Internet]. 12 ago, 2015 [citado em 27 jan. 2020]. Disponível em https://migalhas.uol.com.br/depeso/225012/a-destruicao-da-teoria-das-incapacidades-e-ofim-da-protecao-aos-deficientes

10. Menezes JB, Teixeira ACB. Desvendando o conteúdo da capacidade civil a partir do Estatuto da Pessoa com Deficiência. Pensar. 2016;21(2):568-599. doi https://doi.org/10.5020/2317-2150.2016.v21n2p568.

11. Albuquerque A. Capacidade jurídica e direitos humanos. Rio de Janeiro: Lumen Juris; 2018.

12. Naciones Unidas. Convención sobre los derechos de las personas con discapacidad. Observaciones finales sobre el informe inicial del Brasil - CRPD/C/BRA/CO/1 [internet]. 29 de septiembre de 2015 [citado em 19 dez. 2019]. Disponível em: https://documents-ddsny.un.org/doc/UNDOC/GEN/G15/220/78/PDF/G1522078.pdf?OpenElement

13. Naciones Unidas. Convención sobre los derechos de las personas con discapacidad. $11^{\circ}$ período de sesiones. Observación general $n^{\circ} 1$ - CRPD/C/GC/1: Artículo 12: Igual reconocimiento como persona ante la ley [Internet]. Adoptada el 11 de abril de 2014 [citado em 15.9.2019]. Disponível em: 
procedimentos de requerimento, concessão, manutenção e revisão do Benefício de Prestação Continuada da Assistência Social - BPC. Brasília; 24 set 2018 [citado em 20.jan.2020]. Disponível em: https://www.in.gov.br/materia/lasset_publisher/Kujrw0TZC2Mb/content/id/41971503/do1-2018-09-24-portaria-conjunta-n3-de-21-de-setembro-de-2018-41971236

24. Flores JH. A (re) invenção dos direitos humanos Internet]. Florianópolis: Boiteux; 2009. [citado em 12 dez. 2019]. Disponível em:

https://edisciplinas.usp.br/pluginfile.php/4253519/mod_resource/content/1/Joaquin\%20Herr era\%20Flores\%20-

\%20A\%20reinven\%C3\%A7\%C3\%A30\%20dos\%20direitos\%20humanos.pdf

Figueiredo ACM. A capacidade jurídica das pessoas com deficiência: uma ressignificação necessária à luz dos direitos humanos e do modelo social de deficiência. Cadernos Ibero-Americanos de Direito Sanitário. 2021 jan./mar.;10(1):186202 